\title{
0 jogo como fonte de stress no basquetebol infanto-juvenil
}

\author{
D. De Rose Jr. \\ S.R. Deschamps \\ P. Korsakas
}

Escola de Educação Física e Esporte
Universidade de São Paulo, São Paulo, Brasil

https://doi.org/10.5628/rpcd.01.02.36

\section{RESUMO}

O jogo de basquetebol é uma fonte potencial de stress para atletas. Os diferentes fatores que compõem esse jogo geram situações que podem influenciar no desempenho dos atletas. Neste estudo procurou-se identificar as situações específicas do jogo e que são entendidas como causadoras de stress por atletas infanto-juvenis e classificá-las de acordo com o nível de stress que causam aos mesmos. Participaram do estudo 136 jogadores de basquetebol, com idade variando entre 15 e 18 anos, sendo 61 moças e 75 rapazes, todos vinculados a clubes do Estado de São Paulo e competindo em eventos oficiais organizados pela Federação Paulista de Basketball. Esses atletas responderam ao Formulário para Identificação de Situações de Stress no Basquetebol (FISSB). Os resultados mostraram que as principais situações causadoras de stress estavam relacionadas aos seguintes fatores específicos:

"competência", "dificuldade do jogo"; "arbitragem"; "técnico" e "companheiros de equipe". Apesar de haver diferenças significativas nos níveis de stress apontados pelas meninas, em relação aos meninos, houve uma correlação muito forte entre a classificação das situações ( $r$ = 0.9027; $\mathrm{p}<0.01$ ). Esses resultados mostram a importância do jogo, como fonte de stress e servem para que técnicos e atletas possam melhor entender o processo competitivo e diminuir o impacto dessas situações no desempenho dos atletas.

Palavras-chave: Stress competitivo, basquetebol, esporte infantojuvenil e competição esportiva.

\section{ABSTRACT \\ Game as a source of stress with young basketball players}

The basketball game is a potential source of stress for the athletes. The different aspects of the game lead to situations that can influence the players' performance. In this study the purpose was to identify and rank the game stressful situations, according to the opinion of basketball youth athletes. The research was made with 136 basketball players (61 girls and 75 boys) with age ranging from 15 to 18 years old. All of them were playing basketball for clubs at State of São Paulo and competing in events organized by the regional basketball league. The athletes answered the Formulary for Identification of Stressful Situations in Basketball (FISSB). The results showed that the most stressful situations in the game were related to the following specific factors: "competence", "task difficulty"; "referees"; "coaches" and "teammates". Although there was significant differences in the level of stress between girls and boys, there was a strong correlation between both sexes concerned to the rank of the ( $r s=0.9027$; $p<0.01)$. These results show the importance of game situations as stress source and contribute for the understanding of the competitive process by coaches and athletes in order to decrease the influence of stress in athletes' performance.

Key Words: Competitive stress; basketball; youth sport; sport competition. 


\section{INTRODUÇÃO}

O basquetebol pode ser considerado um esporte complexo, que envolve um processo dinâmico e contínuo de situações específicas. Para atingir um nível de execução considerado adequado os atletas devem estar preparados fisicamente, tecnicamente e taticamente. Esses fatores, aliados aos aspectos psicológicos envolvidos na prática de qualquer esporte competitivo, são decisivos na determinação do desempenho dos atletas e, até mesmo, na definição dos resultados dos jogos.

Entre os aspectos psicológicos que fazem parte de qualquer contexto competitivo, o stress pode ser considerado um dos fatores preponderantes na determinação do desempenho, não se desprezando a influência da ansiedade, da motivação, da agressividade, da concentração, da atenção e da coesão de grupo, entre outros.

Lidar com as situações provocadoras de stress e manter os níveis adequados de ansiedade são fundamentais para a manutenção de um estado aceitável que permita ao atleta, além de desempenhar em níveis apropriados, tomar decisões importantes em diferentes momentos do jogo. Pode-se imaginar que atletas experientes, com grande número de participações em eventos internacionais, tenham melhores condições de lidar com as situações causadoras de stress próprias de uma competição e possam manter seus níveis de ansiedade dentro de padrões aceitáveis. No entanto, a pressão dessas competições pode provocar rupturas nesses comportamentos, pelas consequências que o fracasso nessas situações pode gerar.

Imagina-se também que atletas em início de carreira, apesar de participarem de eventos menos tensos e com consequências não tão importantes, tenham dificuldades em lidar com as situações do contexto competitivo ou externas a ele e que levem a um desempenho inadequado, exatamente pela falta de experiência.

Todas essas considerações despertam o interesse pelo estudo detalhado desse componente presente no processo competitivo, para que se elucidem algumas dúvidas e para que se tenham melhores condições de lidar com as situações causadoras de stress, diminuindo seu impacto no desempenho dos atletas envolvidos.

\section{REVISÃO DE LITERATURA}

Os esportes coletivos caracterizam-se por uma sequência de ações e tomadas de decisão encadeadas com a participação de dois ou mais jogadores (13). O basquetebol apresenta uma grande variação de ações durante o jogo, fazendo com que esta seja uma das mais complexas modalidades esportivas que ainda apresenta limitações relacionadas ao espaço e ao tempo de jogo. O jogo no basquetebol está estruturado com base em três aspectos sequenciais e interdependentes: fundamentos, situações onde ocorre a combinação desses fundamentos e aspectos táticos de defesa e ataque. A boa execução desses componentes estruturais depende basicamente das capacidades físicas, coordenativas e perceptuais, além das habilidades motoras e cognitivas $(4,18)$. Os componentes físicos, coordenativos, perceptuais, técnicos e táticos inseridos nas situações do próprio jogo e aliados às exigências psicológicas, fazem do basquetebol um esporte muito complexo, proporcionando uma gama infindável de análises, inúmeras opções e uma grande variabilidade de situações. Tudo isto exige muita preparação por parte dos atletas, inclusive em relação aos fatores psicológicos envolvidos em sua prática O basquetebol exige três fatores básicos para a sua prática: concentração, controle e confiança. O atleta precisa estar focalizado na tarefa, controlando suas emoções e confiando na sua capacidade de realizá-la. $\mathrm{O}$ atleta tem que ter auto controle e não deixar que as emoções influenciem nas decisões a serem tomadas. É um ajuste delicado entre mente e corpo (18). No contexto competitivo, o basquetebol é um esporte potencialmente gerador de stress, no qual os atletas são solicitados a desempenhar de forma ideal, sob circunstâncias dinâmicas que exigem grande atenção, concentração e participação ativa, mediadas por pressões diversas como tempo de jogo, adversários, arbitragem, além de fatores como necessidade de vencer, obtenção de status social, recompensa e necessidade de reconhecimento, que no conjunto podem afetar o rendimento $(6,16)$. Assim como nos demais esportes coletivos, o basquetebol tem como fontes geradoras de stress as situações direta ou indiretamente relacionadas ao processo competitivo. As situações diretamente relacionadas ao processo competitivo são aquelas 
que acontecem ao longo desse processo, desde o treinamento até o jogo propriamente dito e podem depender exclusivamente do indivíduo ou do ambiente, ou de ambos em uma combinação multivariada de fatores. Já as situações indiretamente relacionadas ao processo competitivo são aquelas que acontecem no cotidiano do atleta e que podem afetar seu desempenho competitivo (6). A literatura especializada não apresenta um número muito expressivo de estudos relacionando basquetebol e situações de stress competitivo, dificultando a análise desse fenômeno. Estudos mostram diversos aspectos da relação stress/ desempenho no basquetebol, como por exemplo situações externas à competição, comportamento dos atletas, situações específicas de jogo, reações e expectativas. Também apresentam amostras variadas em relação ao sexo, faixa etária e nível dos atletas. A maioria foi realizado com atletas adultos de diferentes níveis. Algumas das situações causadoras de stress encontradas nesses estudos são demonstradas a seguir: fadiga (principalmente no final da partida), falta de condicionamento físico, erros técnicos (perder bolas, errar arremessos, errar passes, cometer violações), ser excluído do jogo com 5 faltas, ser substituído por deficiência técnica, perder para equipes de menor expressão técnica, excesso de treinamento, incompatibilidade com técnico e companheiros de equipe e arbitragem $(1,7,10,16,17)$.

Especificamente no Brasil, foi realizada uma pesquisa com jogadores e jogadoras de basquetebol de nível internacional (participantes de Jogos Olímpicos e Campeonatos Mundiais de Basquetebol) na qual foram identificadas 126 diferentes situações de stress das quais 114 referiam-se diretamente ao processo competitivo. Entre elas, 44 aconteciam durante o jogo, mostrando a importância desse momento do processo para os atletas (6). De acordo com essa pesquisa, as situações causadoras de stress específico de jogo foram relacionadas, de acordo com suas características e similaridades a fontes específicas, assim denominadas:
- Importância e dificuldade do jogo (7 situações)

- Competência e dificuldade da tarefa (6 situações)

- Estado físico (3 situações)

- Adversários (3 situações)

- Arbitragem (3 situações)

- Torcida (4 situações)

- Companheiros de equipe (7 situações)

- Técnico (9 situações)

- Infra-estrutura (2 situações)

Portanto, sendo o jogo o momento no qual o atleta demonstra suas habilidades e fraquezas, é nele que muitas situações se concretizam e apontam para uma maior incidência do stress, provocando níveis elevados de ansiedade e preocupações que podem levar a um desempenho inadequado. Isto pode ocorrer tanto em atletas adultos (como mostra a maioria dos estudos citados) como também e, principalmente, com jovens em fase de formação e que ainda não conseguem lidar de forma adequada com as situações estressantes de uma partida de basquetebol.

Estudar a influência dessas situações relacionadas a este momento tão importante é fundamental para que se possa melhor entender o comportamento dos atletas e o quanto ele pode ser afetado quando de sua ocorrência.

Neste estudo, especificamente, procurou-se identificar as situações próprias de jogo que podem causar stress elevado em atletas de basquetebol de categorias de base (cadetes, infanto-juvenis e juvenis), classificar essas situações de acordo com a incidência de respostas dadas pelos atletas ao instrumento utilizado para a finalidade e comparar essa classificação em função do sexo

\section{MÉTODOS}

Antes de se abordar especificamente a metodologia deste estudo é importante que se frise que o fator específico "jogo" e suas fontes e situações de stress fazem parte de um contexto analisado com atletas de nível internacional e que teve prosseguimento com a criação de um Formulário para Identificação de Situações de Stress no Basquetebol (FISSB) para atletas de categorias de base, que será especificado no item "instrumento". 


\section{Amostra}

Participaram do estudo 136 jogadores de basquetebol (75 rapazes e 61 moças) com idade variando entre 15 e 19 anos, todos atletas de clubes filiados à Federação Paulista de Basketball, disputando regularmente campeonatos organizados pela entidade. A média de idade do grupo foi igual a 17 anos e 6 meses.

De acordo com a posição específica, participaram: 35 armadores (bases), 45 pivôs (postes) e 56 alas (extremos). A grande maioria dos atletas tinha experiência de, pelo menos, 4 anos de prática do basquetebol (97-71\%) e somente 1 atleta praticava há menos de um ano. Desta forma pode-se considerar o grupo bastante experiente.

Outro dado importante da amostra é o nível de competição frequentada pelos atletas. Todos, sem exceção, participaram de campeonatos estaduais promovidos pela Federação Paulista de Basketball. Vinte, participaram de torneios nacionais representando a Seleção do Estado de São Paulo; 10 participaram de torneios Sul Americanos representando o país e 11 estiveram em campeonatos mundiais da categoria juvenil.

\section{Instrumento}

Como já foi citado anteriormente, para este estudo foi criado um formulário para identificação de situações causadoras de stress no basquetebol de categorias menores, que teve como base o estudo desenvolvido por De Rose Jr. (6) com atletas adultos de nível internacional, participantes de Campeonatos Mundiais de Basquetebol e Jogos Olímpicos, com a inclusão e adaptação de novas situações em função da faixa etária dos atletas que seriam submetidos às futuras análises (no caso atletas de 15 a 19 anos) e de uma nova fonte de stress, que não foi citada pelos atletas de alto rendimento, mas que por se tratar de jovens poderia causar algum tipo de stress, ou seja, os pais. O Formulário para Identificação de Situações de Stress no Basquetebol (FISSB), como foi denominado, passou por um processo de validação de conteúdo feito por especialistas da área e, posteriormente, pelo processo de análise da consistência interna de seus itens realizado pelo Instituto de Matemática e Estatística da
Universidade de São Paulo que utilizando o índice Alpha de Cronbach, encontrou um valor de 0,98, considerado muito alto para instrumentos dessa natureza (3)

O FISSB foi dividido em 4 partes: 1- ficha de identificação do atleta (anexo 1); 2- questões sobre fatores extra competitivos ; 3 - questões sobre fatores competitivos (anexo 2) e 4- questões abertas sobre níveis de expectativa, objetivos e motivos que levaram os atletas à prática do basquetebol. As situações apresentadas nas partes 2 e 3 foram associadas a uma escala de intensidade de stress, com valores variando de $0=$ não provoca nenhum stress a 5 = provoca stress muito elevado.

Para este artigo foram valorizados somente as questões diretamente relacionadas ao fator “jogo”, conforme classificação apresentada por De Rose Jr. (6).

\section{Procedimentos}

O FISSB foi administrado aos atletas após contato com os técnicos responsáveis e sua autorização para a realização do estudo. Os atletas foram instruídos a respeito do preenchimento do formulário e lhes foi dada a opção de participar ou não do estudo. Aos atletas que concordaram com a participação foi entregue um formulário em envelope fechado, com a recomendação de que tinham que respondê-lo e devolvê-lo no prazo de 15 dias, também em envelope fechado, ao próprio autor.

Ao receberem as orientações sobre o preenchimento do formulário, os atletas tomaram conhecimento do projeto e a garantia da manutenção do sigilo dos dados.

\section{Análise dos dados}

Para atender os objetivos deste estudo, foram consideradas as situações associadas ao fator específico denominado “jogo", de acordo com a categorização pré determinada (6). Este fator, após a modificação e adequação dos itens, é composto por 63 situações (anexo 2).

As situações foram classificadas considerando-se os valores percentuais da somatória das respostas dos níveis 4 (provoca muito stress) e 5 (provoca stress muito elevado). Foi também estabelecida a correlação entre as classificações em função do 
sexo, através do Coeficiente de Correlação de Postos de Spearman.

Realizou-se ainda a comparação dos níveis de stress de cada um dos grupos em função do sexo com a utilização da Análise de Variância (ANOVA).

\section{RESULTADOS}

De acordo com a opinião dos atletas, as situações de jogo que mais causam stress estão relacionadas a fontes como: arbitragem, técnico, competência, dificuldade do jogo e companheiros de equipe. Em ambos os sexos as situações relacionadas a essas fontes específicas se sobressaíram sobre as demais situações, como mostra a tabela 1.

Tabela 1 - Médias dos níveis de stress de cada fonte específica em função do sexo.

\begin{tabular}{lcc} 
Fonte Específicas de Stress & Masc & Fem \\
\hline Competência e Dificuldade do Jogo & 2.93 & 3.26 \\
Estado físico & 2.51 & 2.66 \\
Adversários & 2.19 & 3.09 \\
Arbitragem & 3.31 & 3.45 \\
Torcida & 1.83 & 2.04 \\
Companheiros de Equipe & 2.83 & 3.40 \\
Técnico & 3.10 & 3.60 \\
Pais & 1.25 & 1.22 \\
Estrutura e Local de jogo & 2.34 & 1.97 \\
Média Geral & 2.61 & 2.68
\end{tabular}

O nível de stress atribuído às situações apresentadas no FISSB foi significativamente maior para as jogadoras $(p<0.01)$. Inicialmente pensou-se que esta diferença estivesse relacionada com a situação 43 que se refere especificamente a menstruação. Desta forma, ela foi excluída do indicador de stress e ainda assim a média de stress das mulheres foi maior que a dos rapazes. Através do teste t para comparação de médias, observou-se que a diferença era estatisticamente significante $(t=2,82 ; \mathrm{p}<0.01)$. As tabelas 2 e 3 mostram as 10 situações que causaram mais stress nos meninos e nas meninas, respectivamente. Para este cálculo foram considerados os valores de frequência relativa (\%) da somatória das respostas dos níveis 4 e 5 do FISSB.
Tabela 2 - 10 situações que mais provocam stress em jogo, de acordo com a opinião dos jogadores (valores percentuais)

Cl. Situação

Valor $\%$

1 34-Cometer erros que provocam a derrota da equipe 77.3

2 25-Perder jogo praticamente ganho 68.9

3 31-Repetir os mesmos erros 68.0

4 50-Arbitragem que te prejudica 64.0

5 24-Perder para equipe tecnicamente inferior $\quad 62.7$

6 33-Cometer erros em momentos decisivos 61.3

7 68-Técnico que privilegia determinado jogador $\quad 60.0$

8 60-Companheiro egoísta 58.7

9 30-Jogar abaixo de seu padrão normal 56.0

10 69-Técnico que só critica 54.7

10 70-Técnico que não reconhece o esforço do jogador 54.7

Tabela 3 - 10 situações que mais provocam stress em jogo, de acordo com a opinião das jogadoras (valores percentuais)

Cl. Situação Valor \%

1 31-Repetir os mesmos erros $\quad 88.1$

2 60-Companheiro egoísta 80.3

3 25-Perder jogo praticamente ganho 77.1

4 34-Cometer erros que provocam a derrota da equipe 77.0

5 63-Companheira que cobra ou reclama muito $\quad 73.8$

6 30-Jogar abaixo de seu padrão normal 77.1

7 37-Ser excluída do jogo 70.5

8 24-Perder para equipe tecnicamente inferior $\quad 70.1$

9 68-Técnico que privilegia determinado jogador 65.6

10 70-Técnico que não reconhece o esforço do jogador 64.0

Apesar da diferença do nível de stress para cada situação e de ser esta diferença estatisticamente significante, notou-se que havia forte concordância quanto à ordem dessas situações entre rapazes e moças. Este fato pode ser observado através do valor do Coeficiente de Correlação de Postos de Spearman ( $r s=0.90 ; \mathrm{p}<$ 0.01). Isto também se confirma quando comparada a ordem de classificação das fontes (apontadas na tabela $1)$, onde $r s=0.88(\mathrm{p}<0.01)$.

Algumas situações que a princípio imaginava-se que tivessem uma grande importância e que poderiam ser interpretadas como causadoras de stress não foram citadas com grande frequência e nem com a intensidade esperada. Referem-se especificamente à presença dos pais na competição e à sua participação na vida esportiva dos filhos e à influência da torcida no desempenho desses atletas. 


\section{DISCUSSÃO E CONCLUSÕES}

O resultado que mostra as meninas com maior nível de stress em relação aos meninos é confirmado por outros estudos que compararam variáveis psicológicas entre os sexos, especialmente o stress e a ansiedade. Alguns estudos realizados com atletas brasileiros, na mesma faixa etária, apontam que os níveis de stress e ansiedade são, naturalmente, maiores nas meninas devido a fatores inerentes à própria estrutura dos sexos e também a fatores sociais. É muito comum que a mulher sofra determinadas pressões quando pratica esportes, porque esta ainda é uma atividade muito relacionada ao sexo masculino. Isto faz com que as mulheres tenham que demonstrar mais enfaticamente sua capacidade competitiva. Outro fator que se considera é que a mulher expressa de forma mais sincera seus sentimentos do que o homem, principalmente aqueles relacionados a preocupações, fraquezas e medos $(5,7,8)$.

A fonte que causou níveis de stress mais elevados, tanto para os rapazes quanto para as moças, foi a "arbitragem", que engloba três situações específicas (discussão com árbitros; arbitragem que prejudica você e arbitragem que prejudica a equipe). Esta última é, de todas as situações de jogo a que apresenta o maior peso na definição do índice de stress (3). Outros estudos com jogadores de basquetebol mostram que a arbitragem é um dos fatores mais citados $(6,7,14,16,17)$. Há determinadas situações relacionadas à arbitragem que podem levar o atleta a reações inesperadas e até mesmo agressivas, sendo que alguns atletas as colocam como pontos críticos em suas carreiras esportivas (6).

Ao se analisar cada uma das situações, nota-se que as que estão relacionadas à fonte "competência e dificuldade do jogo" ocupam lugar de destaque entre as mais frequentes, pois dependem quase que exclusivamente do desempenho individual e são elas as responsáveis pela exposição de suas habilidades ou fraquezas, contribuindo, muitas vezes, para o fracasso individual ou coletivo. Este fato também pode ser verificado em outros esportes, principalmente o futebol e o handebol como mostram estudos realizados com atletas de diferentes níveis nesses esportes $(2,6,7,9,15,16,19)$.
Outra fonte muito importante de stress em jogo, segundo os atletas, é o "técnico", pois suas atitudes e posturas podem causar níveis elevados de stress e interferir diretamente no seu desempenho. Técnicos injustos, técnicos que não reconhecem o esforço dos atletas e aqueles que somente criticam sem apontar soluções, parecem contribuir de forma importante para elevados níveis de stress dos atletas durante o jogo no caso dos esportes coletivos, mas também durante as provas típicas de esportes individuais, tais como a natação, o atletismo, a patinação e o remo $(2,7,9,11,12,14,15,19,20)$.

Finalmente, considerando-se as cinco fontes mais importantes de stress observa-se a importância dos conflitos com companheiros de equipe. Egoísmo e cobrança exagerada são os aspectos mais citados e que provocam o maior nível de stress entre os atletas. Outras situações envolvendo companheiros de equipe também são citadas em estudos com atletas de diferentes esportes. Entre elas: discussões, inveja e prepotência $(2,6,9,11,19)$.

Em relação a ordem das situações de jogo causadoras de stress, em função da frequência relativa das respostas nos níveis 4 e 5 do FISSB, ficou nítido, pelo resultado da correlação que, apesar da diferença dos níveis de stress, há uma concordância na classificação dessas situações, mostrando que pode haver um perfil definido daquilo que, efetivamente, causa stress em situações específicas de jogo.

Este resultado também foi obtido em estudos com identificação de sintomas de stress pré-competitivo em atletas infanto-juvenis, demonstrando que as situações e os sintomas de stress, apesar de serem identificados em diferentes níveis, aparecem em uma ordem muito similar em ambos os sexos $(5,8)$.

\section{CONCLUSÕES}

Como era de se esperar, as ocorrências de jogo são muito marcantes pois têm uma influência direta no resultado e na avaliação a qual os atletas são submetidos. Ou seja, o que acontece em jogo é muito mais evidente do que aquilo que acontece em treinamento ou em qualquer outra situação na qual o atleta não esteja exposto diretamente. Além disto, verificou-se que a incidência das respostas nos níveis mais elevados de stress foi significativamente maior nas meninas, reforçando o 
resultado de outros estudos que apontaram este resultado.

No entanto, a ordem de classificação das situações, apesar da diferença de nível de stress, apresentou uma concordância muito grande, atestando que existe uma opinião muito parecida sobre o que provoca realmente stress em jogo.

Todos os resultados e conclusões obtidas a partir deste estudo servem como subsídio para que técnicos e atletas entendam melhor o processo competitivo, sob o ponto de vista do stress causado por ele, e possam trabalhar para diminuir seu impacto sobre o desempenho dos atletas, melhorando seu resultado final e, consequentemente, o de sua equipe.

\section{NOTA}

(a) Esta terminologia é adotada pela Federação Paulista de Basketball (Brasil) para identificar atletas com idades variando de 15 a 19 anos.

\section{CORRESPONDÊNCIA}

\section{Dante de Rose Jr.}

Rua Rio Grande do Sul, 770, ap. 113

09510-021 São Caetano do Sul - São Paulo

Brasil

[danrose@usp.br] 
ANEXO 1 - FORMULÁRIO PARA IDENTIFICAÇÃO DE SITUAÇÕES DE STRESS NO BASQUETEBOL

Ficha de identificação de atleta

Nome:

Nasc. $M() F()$

Escolaridade: $1^{\circ}$ grau ( ) série $2^{\circ}$ grau ( ) série $3^{\circ}$ grau ( )

Clube/entidade:

Telefone para contato:

email:

Posição:

Há quanto tempo pratica Basquetebol?

1. menos de 1 ano

2. 1 a 2 anos

( )

3. 2 a 3 anos

4.3 a 4 anos

5. 4 a 5 anos

6. mais de 5 anos

Qual o nível mais alto de competição que você já participou?

1. Municipal

2. Estadual

3. Nacional

4. Sulamericano

5. Panamericano

6. Mundial

7. Olimpíada

Você já participou de Seleções? Sim ( ) Não ( )

$$
\text { Regional/Estadual Nacional }
$$

Quantas vezes?

$1^{\mathrm{a}}$ vez (ano)?

última vez (ano)?

Data:
(
( )
( )
( ) 


\section{ANEXO 2 - FORMULÁRIO PARA IDENTIFICAÇÃO DE SITUAÇÕES DE STRESS NO BASQUETEBOL}

II - Situações competitivas de stress - "jogo"

Jogos decisivos ....

Momentos decisivos d

Jogo fácil que complica.....

Perder para uma equipe tecnicamente inferior

Perder jogo praticamente ganho

A competição em si .

Sair com cinco falta

Ficar na reserva

Ser substituído

Competir/jogar abaixo do seu padräo norma

Cometer erros técnicos (errar arremessos, errar passes)

Cometer erros em momentos decisivos

Cometer erros que provocam a derrota da equipe ...........

Cometer violações (andada, 3 segundos, 2 saídas, etc)

Tomar falta técnica

Ser excluído do jogo .....

Não tentar $(0 \mathrm{~m}$

estado físico

Jogar contundido ...

Jogar doente .

Jogar menstruada

Adversário desleal

Adversário convencido

Adversário provocador.

Discussão com adversário

Arbitragem prejudica a sua equipe ou um companheiro

Arbitragem prejudica você

Discussão com árbitros

Torcida a favor que comete injustiça

Torcida a favor que cobra muito

Falta de reconhecimento da torcida

Agressões físicas e morais por parte da torcida...............

Manifestações da torcida contrária.

Omissão de um companheiro de equipe

Displicência de um companheiro de equipe

Companheiro que não cumpre seu papel no jogo

Companheiro egoísta

Companheiro que não se esforça

Companheiro que não entende o que você quer fazer .

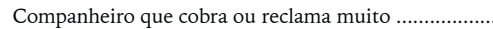

Técnico que cobra em exagero

Técnico que comete injustiças com jogado

Técnico que não deixa claro papel jogador na equipe

Técnico que não deixa jogador à vontade na quadra .

Técnico que privilegia determinado jogador ...................

Técnico que só critica

Técnico que não reconhece esforço do jogador ..........

Técnico que só enxerga o lado negativo

Técnico que não sabe lidar com a equipe .....

Técnico que toma decisões erradas ou que não sabe tomar decisões ......

Técnico que grita muito .

Presença do seu pai no jogo

Presença da sua mãe no jogo

Interferência dos pais no seu desempenho

Pais que dão palpites (conselhos) durante o jogo... .

Pais que gritam muito durante o jogo ..........

Pais que cobram muito durante oj

Local inadequado para competiçôes (quadra, piso,

iluminação, vestiários)

Material inadequado jogo (bolas, aparelhos, uniforme)

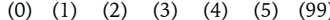

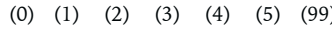

$\begin{array}{llllll}(0) & (1) \quad(2) & (3) & (4) & \text { (5) } & (99)\end{array}$

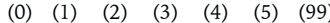

$\begin{array}{llllll}(0) & (1) \quad(2) & \text { (3) } & \text { (4) } & \text { (5) } & \text { (99) }\end{array}$

$\begin{array}{llllll}(0) & (1) \quad(2) & (3) & (4) & \text { (5) } & \text { (99) }\end{array}$

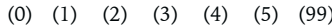

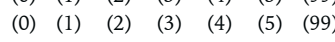

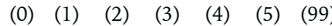

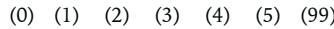

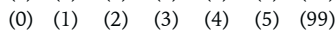

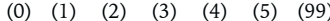

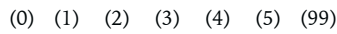

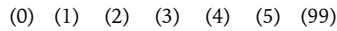

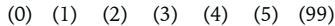

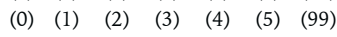

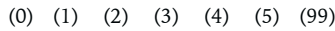

$\begin{array}{llllll}\text { (0) } & \text { (1) (2) (3) (4) (5) } & \text { (99) }\end{array}$

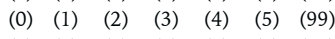

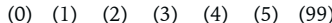

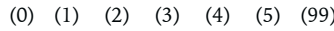

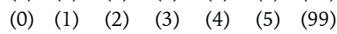

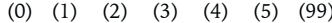

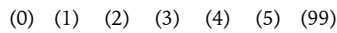

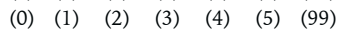

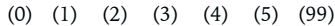

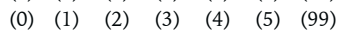

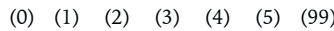

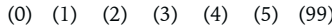

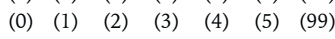

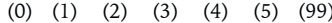

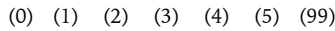

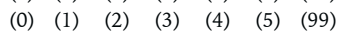

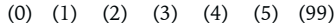

$\begin{array}{llllll}(0) & (1) \quad(2) & \text { (3) } & \text { (4) } & \text { (5) } & \text { (99) }\end{array}$

$\begin{array}{llllll}(0) & (1) \quad(2) & \text { (3) } & \text { (4) } & \text { (5) } & \text { (99) }\end{array}$

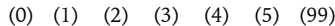

$\begin{array}{llllll}(0) & (1) \quad(2) & \text { (3) } & \text { (4) } & \text { (5) } & \text { (99) }\end{array}$

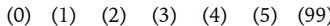

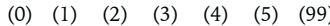

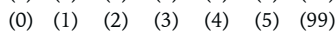

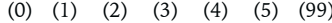

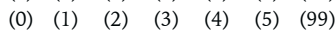

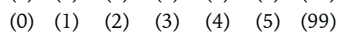

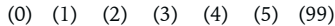

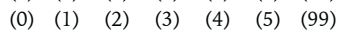

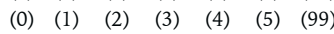

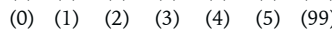

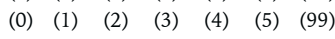

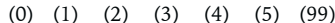

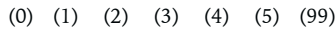

$\begin{array}{lllll}(0) & (1) & \text { (2) (3) (4) (5) } & \text { (99) }\end{array}$

$\begin{array}{llllll}(0) & (1) \quad(2) & \text { (3) } & \text { (4) } & \text { (5) } & \text { (99) }\end{array}$

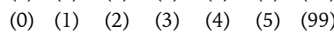

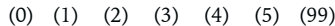

$\begin{array}{llllll}(0) & (1) \quad(2) & \text { (3) } & \text { (4) } & \text { (5) } & \text { (99) }\end{array}$

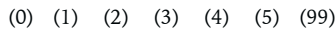

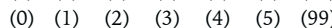

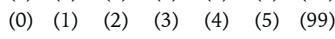

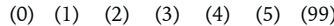

(0) (1) (2) (3) (4) (5) (99)

$\begin{array}{llllll}(0) & (1) & \text { (2) } & \text { (3) } & \text { (4) } & \text { (5) }\end{array}$

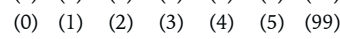

(forma reduzida - o original contém 140 situações competitivas) 